\title{
The role of organizational agility on the relationship between organizational information technology capabilities and competitive performance; case study: Mellat bank
}

\author{
Roya Babazadeh and Saeed Jafari Titkanloo \\ Faculty of Management, Imam Reza International University, Mashhad, Iran \\ Email: s_jafari_t@imamreza.ac.ir
}

\section{ABSTRACT}

This study aimed to investigate the role of organizational agility in relation between organizational intelligence capabilities and competitive performance in Mellat Bank. This research was descriptive survey. The community consists of two groups of experts of the central organization and managers of Mellat Bank Branches in Mashhad. In total, the population of this study was 367 people, and 225 people were selected using available sampling. The tool used in this research was a researched-based native-based questionnaire. Its factual validity, using the views of professors and experts, verified the structure through confirmatory factor analysis and its reliability through the Cronbach's alpha coefficient was examined and confirmed. Took The data analysis method was structural equations through the software PPS; the results of path analysis indicated that the IT capability of the organization has a positive and significant effect on market agility and its operation. Also, agility in operations can affect agility in the market and agility in the market can lead to high competitive performance.

\section{Original Article}

PII: S232247701900004-9

Rec. 22 September, 2019

Acc. 10 November, 2019

Pub. 25 December, 2019

\section{Keywords}

Competitive performance, Agility in operations, Agility in the market, The ability of information technology

\section{INTRODUCTION}

Today's world with such features as widespread change, increasing complexity, and increasing levels of competition create a dynamic environment for the organization, so that the success of organizations depends on the coherence and compatibility with such an environment. On the other hand, the severe changes in the economic environment and the high level of competition in recent years have made it necessary for agility to succeed. In today's environment, with organizations facing a global competitive environment, there is always a need for rooted changes and creative creativity. Also, the use of competitive performance is the most important factor in achieving them in the competitive advantages of the industry (Rezaian and Ashouri, 2013).

According to White, agile information systems are considered as an essential factor in the development and agility of the organization, and without them implementing speed and agility in the organization. It will be impossible (Saha et al., 2016). Information technology emerged as an essential element in developing countries such as Iran to support the need for genuine, systematic information in commerce and industry, and has taken important roles as a tool for creating value in business activities (Bernstein et al., 2016). Information technology plays an essential role in the development of agility, without which it would be impossible to achieve the speed and flexibility of agility concepts. The foundation of the agile organization is the integrity of the information system, technology, individuals, business processes and equipment in the Harmonic Organization to quickly respond to events and environmental changes. Agility wants the organization to rush and accelerate the integration of technology and staff with communication infrastructure to respond to changing customer needs in a market environment that is subject to constant and unpredictable changes (Nadkami and Barr, 2008).

In other words, changes in today's business environments that stem from changes in customer needs lead to uncertainty in decision-makers, and organizations that focus on speed, more flexibility and investment accountability they are more likely to achieve their goals. Among the use of information and communication technologies in delivering services to increase productivity, flexibility and improve the performance of the organization, it is necessary in the IT era. 
On the other hand, in the face of growing consumer expectations of the banking system of the country, banks, including the Mellat Bank, face a variety of financial and operational constraints. Expensive advertising budgets, the necessity of building new branches, multiple banks and electronic banks, monitoring competitors' movements and timely response to it and, ultimately, macroeconomic problems of the country that have an undeniable effect on instability. There are many banking issues that Mellat Bank faces, like other banks. In such a situation, it is only possible to ensure the growth and survival of the bank by focusing on providing agile and quality services, and in some ways increasing the efficiency of banking operations and avoiding unnecessary costs for customers with marginal profitability. The In fact, the development of technology has made fundamental changes in the provision of services by banks, and the Mellat Bank, given its internal systems and its applied technologies, demonstrates flexibility in terms of environmental changes and competitive conditions, can agility in operations And agility in providing services and thereby enhance its competitive performance; indeed, the main issue of this research is that what is the effect of Mellat Banking Information Technology on agility and agility on the competitive performance of the Mellat Bank?

\section{Definitions of variables}

Competitive performance: Competitive performance represents a set of ideal criteria for innovative performance, product performance, and sales marketing (Shan and Jolly, 2015). Competitive performance implies competitive advantage, in so far as the organization is able to develop itself more than competitors (McGinnis and Vallopra, 1998).

Organizational Agility: Many researchers have worked in this field, and each has provided several definitions of agility, here the accepted definition refers to the ability of the producer to react quickly to sudden and unpredictable changes (Amirnezhad and Dragon, 2016).

Operational agility: Defining agility in operations on theoretical foundations involves two basic concepts: responding to changes (unpredictable and unexpected) with appropriate methods at the right time and exploiting change and taking advantage of change as an opportunity (Khoshlahn and Ardabili, 2016).
Agility in the market: To reflect the effectiveness and effectiveness of the organization's actions to respond to changes in market patterns and flows. Operationally, this variable is measured through the following three components:

1. Reaction speed relative to market changes

2. Continuous monitoring of rivals

3. Opportunity and exploitation of market turbulence (Mikalef and Pateli, 2017).

IT capabilities: Bharayha (2000) believes that information technology capabilities are related to the ability of a company to mobilize and deploy ITrelated resources in their integration with other resources and other capabilities (Faramarzi, 2016).

\section{Relationship between variables}

In order to achieve both types of agility, it is imperative to process the volume and extent of distributed information in an efficient way and quickly apply flexible business processes and efficiently coordinate tasks between dispersed geographic units. These activities can be enhanced with a number of IT capabilities (Roberts and Grover, 2012). Based on this theory, IT capabilities can potentially help promote the development of fit in the organization with the environment; therefore, information technology can be a major ability to create organizational agility by integrating with monitoring, support, Learning, integration and review (Weill et al., 2002). As a result, ICT capabilities are expected to be synergistic and one of the main factors influencing agility of the organization in two dimensions is agility in the market and agility in operations. For example, through these capabilities, it can be ensured that competitors are closely monitored and sufficient information is provided from customers for use in managerial decisions. Strong IT-enabled companies will be able to set up internal operations to respond to potential changes in the business environment, and will benefit from investing in the market with new or improved value propositions as a result of focusing on their capabilities. However, the response to change often means that coordination of activities in different units or functions is required. Also, companies with a strong IT capability will be able to constantly assess and monitor the environment and improve their knowledge base, engaging or not to participate in achieving more agility in the market and agility in operations (Lavie and Rosenkopf, 2006).

Operational agility, in addition to facilitating faster adaptation of domestic business processes, enables IT organizations to achieve better business 
processes through robust sequencing and rapid business operations throughout the value chain. Wealth and large processes lead companies to enhance their participation and use of IT capabilities to search faster and integrate their competencies into the value chain. In addition, this kind of agility makes the knowledge upgraded in the organization and improves by creating interconnections in the virtual markets and making informed and quick decisions in the marketplace and investing in it (Zott et $\mathrm{al}, 2011$ ).

It is generally believed that organizational agility is very beneficial for organizations by enabling organizations to restructure and regulate their activities in line with changing business environments, which ultimately lead to superior performance over competitors. By enhancing organizational agility, organizations will be better able to identify competitive opportunities in their target market and gain a better place by utilizing the competencies and resources needed to exploit these opportunities (Sambamurthy et al., 2003). Agility in the market leads to the benefits of being first through increased product customization, lower delivery performance, and reduced response time. In other words, high agility in operations helps organizations to respond to their changing needs by creating a coalition, improving operational flexibility, lowering costs, and increasing customer retention. In fact, organizational agility enables organizations to invest in market changes by providing new value and helping improve internal activities and align with these changes in the market (Lu and Ramamurthy, 2011). Organizations will be able to enhance their organizational agility. Which expands its competitive practices and gains more in competitive environments. As a result, both organizational agility contributes to competitive victories (Mikalef and Pateli, 2017).

In a research entitled "The Role of Technological Innovation Capabilities in Promoting Innovation Performance of Knowledge Based Companies", it was concluded that the capabilities of strategic planning, $\mathrm{R}$ and $\mathrm{D}$, resource allocation, marketing and learning can significantly improve the performance Improve innovation (Ebrahimi Nejad and Peasant Soltani, 2018).

In a research entitled "Influence of Information Technology Functionality on Performance with the Organizational Agility Intermediary in Bank of Commerce", it was concluded that IT capabilities could affect organizational performance through organizational agility (Kashani Nejad and Rastghoo Kashani, 2017).
In a research entitled "Effect of operational agility on organizational performance in service organizations", it was concluded that organizational measures, technology, customer empowerment and human resources (with the highest impact) as organizational agility dimensions have a significant effect on the performance of organizations (Arjlou et al., 2017).

In a study entitled "Investigating the Relationship between Information Technology and Organizational Agility in the Mahabad Agricultural Bank", it was concluded that there is no relationship between Flexible Information Technology at the SADERAT Bank of Mahabad (Toure and Khalili, 2016).

In a study entitled "Investigating the effect of organizational learning on organizational performance with regard to organizational agility mediators", it was concluded that organizational agility has an impact on organizational performance (Mohammadi Moghaddam et al., 2016).

In a research entitled "Influence of Information Technology Abilities on Business Agility", it was concluded that the four architectural capabilities, infrastructure, human resources and communication resources are the dimensions of the capability of information technology as well as the three sensors, responsiveness and learning Dimensions constitute organizational agility and there is a meaningful relationship between the capabilities of information technology and organization agility (Magnificient et al., 2015).

In a study entitled "Designing Operational and Market Agility Modeling to Improve Competitive Performance", it has been concluded that dynamic capabilities have a significant effect on agility in the market and operational agility (Elahe and Osanlou, 2014).

In a study entitled "Investigating the Relationship between the Data Dimension (Database) of Management Information Management Systems and Organizational Agility in Sirjan Higher Education Centers", it was concluded that there is a positive and significant relationship between the dimension of data in management information systems with organizational agility (Ghanadzadeh and Ya'gubipour, 2013).

In a study titled "Challenges for Organizational Agility and Competitive Performance," for organizations with small and medium resources with limited resources, agility of the organization makes these organizations more resistant to the changing environment outside. Open your doors to serious opportunities. In fact, agility is effective on their competitive performance (Appelbaum et al., 2017). 
A study entitled "Organizational agility and HR strategies in competitive performance" concluded that organizational agility and human resources strategies can create beneficial changes and affect the performance of the organization (Saha et al., 2016). The community of this research is composed of New Delhi's staff and a researcher-made questionnaire was used to collect data. The results of this research indicate that organizational agility and human resource efficiency are important and can affect the organization's ultimate competitive performance.

In a research entitled "Dynamic Information Technology Performance and Its Effect on Competitive Performance", it was concluded that in addition to confirming the role of intermediary agility in operations and market agility in the relationship between information technology capabilities and competitive performance, agility in operations It also has an impact on market agility (Mikalef and Pateli, 2017).

In a study entitled "Recognizing the Relationship between Information Technology Functionality and Operational Agility through Multiple Approaches", it was concluded that IT capabilities could lead to agility in operations (Gong et al., 2017).

A study entitled "Operational Capacity Based on the Capacity of Information Technology" concluded that the ability of information technology in an organization could lead to agility in its operations (Tan et al., 2017).

A research entitled "Information Competitiveness, Organizational Ability and Organizational Agility and Environmental Effects on Performance Extreme" came to the conclusion that in state-owned banks, innovation has a direct relationship with organizational agility, and agility has a positive impact on the performance of organizations (Ravichandran et al., 2007).

A study entitled "Agility Enhancement with Information Technology Capabilities" concluded that timely information sharing through improving the stability and performance of the supply chain would enhance the agility of the organization. The community of this research is staffed by the Shanghai Insurance Bureau and uses a questionnaire to collect information. The IT structure consists of three components of system capabilities, the range of technology, and the IT coalitions, which examine its impact on agility, which includes four components of speed, accountability, flexibility and competence ( $\mathrm{Li}$ et al., 2006).

In a research entitled "IT Influence and Innovation Performance: With the Role of Market
Oriented Mediation", it was concluded that due to the impact of information technology capabilities on marketability and the impact of market orientation on the organization's innovative performance, Information technology can have an impact on innovative performance (Wang et al., 2013).

In the conceptual model of this research, the competitive performance of the dependent variable and the ability of the enterprise IT technology are independent variables, in which two agility variables in the market and agility in the role of the role play. Agility in the market refers to the agility of out-ofcompany actions, and agility in operations to agility in internal organization actions. These relationships are based on research (Mikalef and Pateli, 2017) in Figure 1.

\section{Research hypotheses}

- The ability of Mellat Banking Information Technology has a positive and significant effect on agility in the market.

- The ability of Mellat Banking Information Technology has a positive and significant effect on agility in operations.

- Agility in the operations of the Mellat Bank has a positive and significant effect on agility in the market.

- Agility in the nation's bank market has a positive and significant effect on competitive performance.

- Agility in Mellat operations has a positive and significant effect on competitive performance.

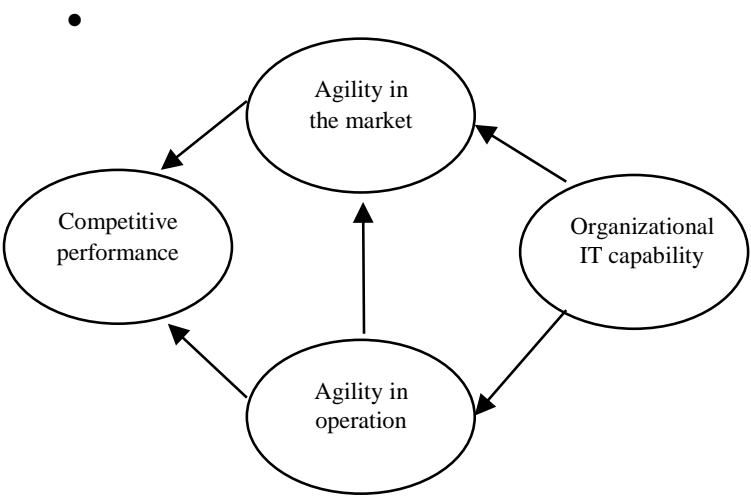

Figure 1. Conceptual model of the research adapted from (Mikalef and Pateli, 2017).

\section{METHODOLOGY}

This research is based on the nature and type of research from the point where it intends to investigate the impact of negative factors and 
negative oral advertising on brand change with the role of mistrust and negative emotions. It is a type of applied research and since it is used in explaining the conceptual model Different research has been used and a model has been developed. Therefore, it could be said that this research is also of a type of developmental research. Since the purpose of this research is to describe the circumstances and phenomena examined in order to better understand the existing conditions and contribute to the decision-making process, this research, based on how the data can be obtained, can be described as descriptive and It also counted a survey. Because it seeks to assess the impact between the variables of the organization's IT capability and agility in the market, agility in operations and competitive performance.

The statistical population of this research includes all relevant managers and experts in the Central Bank of Mellat Bank of Mashhad $(2 \times 32 \times 46)$. The heads and authorities of the Mellat Bank Mashhad branch offices and facilities $(121 \times 107 \times 3)$. In fact, it can be said that the society consists of two groups of officials and experts of the Mellat Bank (Figure 2) and the second group of managers of Mellat Bank Branches in Mashhad. In total, the total population of the survey is 367 people.

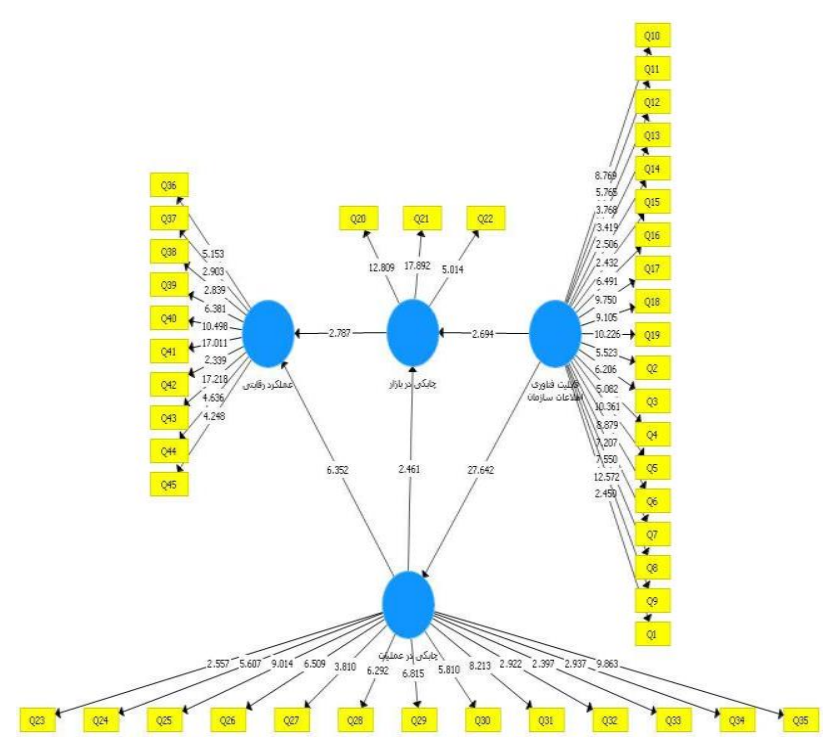

Figure 2. Significance of path coefficients (t statistics)

In this research, a sampling method is used to select the sample. The reason for using this sampling method is that, since not all experts and authorities participate in answering, the questionnaires are distributed electronically and paper to the people who are available. The sample size is based on 5 to 10 times the number of items in the structural equations, which is 5 times the total number of cylinders (45). For this purpose, 225 questionnaires were distributed among the sample members and based on statistical analysis using SPSS and PLS software.

In order to collect data, we use a standard questionnaire based on the Likert scale of five options (I completely disagree, 1 disagree, 2; I have no opinion; 3 agree; 4; and I totally agree; 5) as the main tool for collecting Data has been used. The questionnaire consists of two parts; the first part consists of the questions related to the individual information of the respondents, and the second part includes the questions related to the variables of the research, which was used to ensure the validity of the questions from the guidance and opinions of the professors and relevant experts.

\section{RESULTS}

Frequency and frequency of respondents based on gender show that men constitute the highest percentage of respondents (72.9\%) and women make up 27.1\% of respondents. Age descriptive statistics show that the highest number of respondents in the age group is between 31-40 years old and the lowest in the age group of under 21-30 years old. In addition, in the first part of the questionnaire, customers were asked to indicate their level of education. $4 \%$ were competent and lower, $44.9 \%$ had undergraduate degrees, $24 \%$ had undergraduate and $27.1 \%$ had doctoral degrees. The question of the work experience of the subjects showed that $8.4 \%$ of the subjects were less than 5 years old, $48 \%$ between 5 to 10 years and $43.6 \%$ more than 10 years of work experience.

\section{Test of hypotheses}

Significant evaluation of Pyala's parameters in the Smart Pialas software is done through the automatic startup algorithm or BT. This algorithm is created by re-sampling or replacing the original sample. This command consists of samples with the same number of units as the original sample. The number of retries must be specified by the user. The default value of the software is 200 , but a higher number (like 500) can provide a more reasonable estimate of standard errors. The nonparametric automated setup procedure in the PLS-PM model is the basis for statistical inference. One of the correlation indices in the structural model is the significance of the path coefficients.

Significance of the complementary paths is significant for the sign of the beta coefficient of the 
model. If the obtained value is above the minimum of the statistics at the confidence level, that relationship or hypothesis is confirmed. At 90\%, 95\% and 99\%, this value is compared with the minimum statistic of 1.64, 1.96, and 2.58, respectively. As can be seen, Fig. 8 shows the statistical values of $t$. The basis for the rejection or confirmation of the hypotheses will then be based on a $95 \%$ confidence level.

As can be seen, Figure 3 shows the structural path coefficients. The path coefficients are the same as standard beta in linear regression. The path coefficients should be considered in magnitude, sign and meaningful. The positive path coefficients (positive beta) indicate the direct relationship between the intrinsic and extraneous hidden variables. In contrast, negative path coefficients (negative beta) indicate the inverse relationship between the intrinsic and extraneous hidden variables. This value is greatly indicative of the power of the relationship, which, with the establishment of indirect relations, reduces the magnitude of the beta coefficient. As can be seen, Figure 3 shows the standard estimation coefficients that indicate the effect of each variable on the other variable.
The summary of the results of the hypotheses is presented in Table 1.

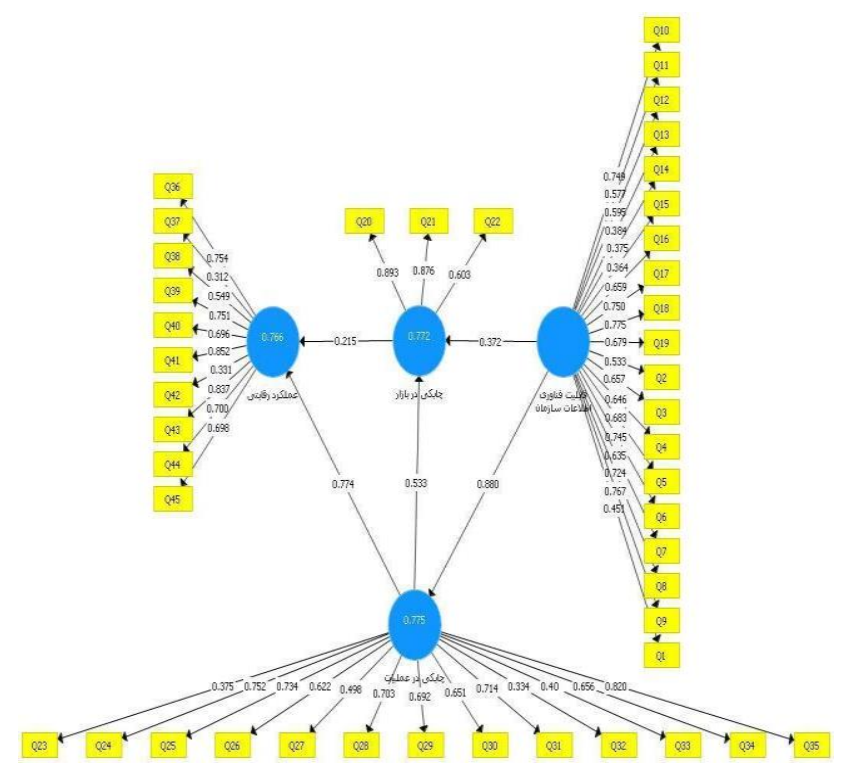

Figure 3. Structural path coefficients

Table 1. the result of the clearance and rejection of the main hypothesis

\begin{tabular}{|c|c|c|c|c|c|}
\hline & Hypothesis S & $\begin{array}{c}\text { Meaningful } \\
\text { (statistics } \mathbf{Y} \text { ) }\end{array}$ & $\begin{array}{c}\text { Path } \\
\text { coefficient }\end{array}$ & $\begin{array}{c}\text { confidence } \\
\text { level }\end{array}$ & Results \\
\hline 1 & $\begin{array}{l}\text { Organizational IT capability } \\
\text { Agility in the market }\end{array}$ & 2.694 & 0.372 & $95 \%$ & Confirmation \\
\hline 2 & $\begin{array}{l}\text { Organizational IT capability } \\
\text { Agility in operation }\end{array}$ & 27.642 & 0.88 & $95 \%$ & Confirmation \\
\hline 3 & $\begin{array}{l}\text { Agility in operation } \\
\text { Agility in the market }\end{array}$ & 2.461 & 0.533 & $95 \%$ & Confirmation \\
\hline 4 & $\begin{array}{l}\text { Agility in the market } \\
\text { Competitive performance }\end{array}$ & 2.787 & 0.215 & $95 \%$ & Confirmation \\
\hline 5 & $\begin{array}{l}\text { Agility in operation } \\
\text { Competitive performance }\end{array}$ & 6.352 & 0.774 & $95 \%$ & Confirmation \\
\hline
\end{tabular}

\section{a DISCUSSION AND CONCLUSION}

Information technology is a key factor in promoting market agility and the ability to drive or hinder market agility. A review of the three-wave literature on various research on the relationship between IT capability and market agility. The first wave of research shows that IT capability not only does not help to promote agility of the business, but also in some cases causes damage. The second wave of research suggests that IT capability brings a high degree of market agility. The third wave of information technology research suggests that although IT capability leads to a high degree of market agility, this relationship is influenced by the degree of assurance of circumstances and events. The first goal of this study was to investigate the impact of IT on agility in the market. Based on the results of the data analysis, the T-value of this path was 2.694 which indicates the significance of this effect. This result is in line with the results of the research (Mikalef and Pateli, 2017; Mokhtarian 
Dehkordi, 2017; Kashani Nejad and Rastghoo Kashani, 2017; Magnificent et al., 2015; Ghanadzadeh and Ya'gubipour, 2013).

Information technology is in fact a kind of technology that is inclusive and its unique feature is its inclusion and necessity. The range of changes resulting from this phenomenon is very diverse and involves the substitution of information instead of energy or manpower in the industrial sector up to the change in the internal sector of the service from personnel services to social services and distribution systems. Operational agility also refers to the responsiveness, efficiency, and effectiveness of the organization's efforts to modify and review the internal operations of the organization when needed. The second goal of this study was to investigate the effect of the organization's IT capability on agility in the operation. Based on the results of the data analysis, the T-statistic was 276.22 , the second hypothesis of the research was confirmed. This result is in line with the results of the research (Mikalef and Pateli, 2017; Mokhtarian Dehkordi, 2017; Kashani Nejad and Rastghoo Kashani, 2017; Toure and Khalili, 2016; Gong et al., 2017; Tan et al., 2017).

The agility in the operation refers to the reaction, effectiveness and effectiveness of the organization's efforts to modify and review the internal operations of the organization when needed. Agility in operations can have a positive effect on agility in the market. The third goal of this study was to investigate the agility of operations in agility on the market. Based on the results, the T-value was obtained at 2.461. Given that this value is greater than 1.96, this assumption is confirmed and agility in the operation has a significant effect on agility in the market at 95\% confidence level. This result is in line with the results of the research (Mikalef and Pateli, 2017).

Competitive performance represents a set of desirable criteria for innovative performance, product performance, and sales marketing. Competitive performance implies competitive advantage, such that the organization is able to develop more than competitors. This competitive performance can be affected by agility in the marketplace. Based on the results of the study, the Tstatistic in this path was 2.787 and, given the significance of this T-statistic, the fourth hypothesis of the research is confirmed. This result is consistent with the results of the research (Mikalef and Pateli, 2017; Appelbaum et al., 2017; Ravichandran et al., 2007).

The competitive advantage enhances the manufacturer's ability to provide a high level of customer service, leading to competitive performance. Other researchers have suggested competitive performance of the organization as a competitive advantage with the perspective of value and quality, and its main elements are axial cost, core product, and core services. Agility in operation can affect competitive performance. The final goal of this study was to investigate the effect of agility on operations on competitive performance. Based on the results of the data analysis, the value of the T-test was 6.352, which means confirmation of the last hypothesis. This result is in line with the results of the research (Mikalef and Pateli, 2017; Arjlou et al., 2017; Elahe and Osanlou, 2014; Appelbaum et al., 2017).

\section{Recommendations}

It is recommended to confirm the first hypothesis:

- Focused on the use of ICT capabilities.

- If banks are to succeed in confronting their challenges and issues, their management training should focus more on using the IT capabilities of the organization to influence the agility of the market, and by discovering the barriers to this important action Basic things to do.

- It is suggested that objective variables be measured such as deposit absorption, profitability, attracting customers, reducing claims, increasing customer etc. Information technology capabilities, such as developmental issues, have a strong impact on senior management support.

Considering the confirmation of the second hypothesis of the research it is suggested: - Management of Banks. Educational Strategies Improve the IT capabilities and adapt them to the needs and expectations of employees to take into account the capabilities of the new technology and pay more attention to qualitative aspects than IT capabilities to agility in the operations of staff.

Considering the confirmation of the third hypothesis of the research it is suggested:

By creating workshops to increase employee agility, they will increase the agility of operations and agility in the market. In this process, arrangements should be made to strengthen monitoring during implementation.

Considering the confirmation of the fourth hypothesis of the research it is suggested: - Employers will attract employees who can agility in the market, which will affect the competitive performance of the bank. Therefore, the bank should increase competitive performance by taking into 
account the competitive environment and economic environment.

In the context of research suggestions from this research, it can be argued that this research has been done in the field of banking. It is suggested that such research be carried out in other industries and the results should be compared with the results of this study. It is recommended that in future research, technical and managerial capabilities.

\section{REFERENCES}

Amirnezhad, Gh. and Dragon, P. (2016). Investigating the Effect of Organizational Structure on Organizational Chalabi in Islamic Azad Universities in Khuzestan Province. Social Development, 11 (1), 165-188.

Appelbaum, S.H., Calla, R., Desautels, D., and Hasan, L. (2017). The challenges of organizational agility (part 1). Industrial and Commercial Training 49 (1), 6-14.

Arjlou, M., Feizi, K., Kazazi, A. and Taqavi Fard, M. T. (2017). Effect of operational agility on organizational performance in service organizations. Managing tomorrow, 16, 1-22.

Bernstein, E., Bunch, J., Canner, N., and Lee, M. (2016). Beyond the holacracy hype. Harvard Business Review, 94 (7), 38-49. Google Scholar

Ebrahimi Nejad, M. and Peasant Soltani, M. (2018). Role of technological innovation capabilities in enhancing the innovation performance of knowledge-based companies. Public Management Research, 11 (41), 83-109.

Faramarzi, M. (2016). Investigating the Influence of Information Technology Capabilities on Innovative Performance by Interacting Organizational Entrepreneurship and Modifying the Competitive Severity. Master's thesis, Ferdowsi University of Mashhad, Iran.

Ghanadzadeh, F. and Ya'qubipour, A. (2013). Investigating the relationship between the data dimension (database) of management information systems and organizational agility in Sirjan higher education institutions. International Conference on Political Epic and Economic Epic, Tehran.

Elahe, S. and Osanlou, B. (2014). Design of operational agility model to improve competitive performance. Management and Development Process, 27 (3), 101-128.

Gong, Y. Y., Mao, H., Titah, R., \& Yao, Y. O. (2017). Understanding the Relationship between IT Capabilities and Operational Agility: A Multi-Method Approach. Hongyi and Titah, Ryad and Yao, Yuliang, Understanding the Relationship between IT Capabilities and Operational Agility: A Multi-Method Approach (September 2, 2017). Google Scholar

Tan, F.T. C., Tan, B., Wang, W., and Sedera, D. (2017). IT-enabled operational agility: An interdependencies perspective. Information and Management, 54 (3), 292-303. https://doi.org/10.1016/j.im.2016.08.001, Google Scholar

Grewal R., and Tansuhaj, P. (2001). Building organizational capabilities for managing economic crisis: The role of market orientation and strategic flexibility. Journal of Marketing, 65 (2), 67-80.

Kashani Nejad, P. and Rastghoo Kashani, F. (2017). Influence of IT capabilities on organizational performance with the role of organizational agility mediator in Trade Bank. Modern Engineering Engineering, 5 (1), 1-16.

Khoshlahn, M. and Ardabili, F. S. (2016). The role of organizational agility and transformational leadership in service recovery prediction. "Proceedings - Social and Behavioral Sciences", 230 (1), 142-149

Lavie D., and Rosenkopf, L. (2006). Balancing exploration and exploitation in alliance formation. "Academy of management journal", 49 (4), 797-818.

Li, G., Lin, Y., Wang, S. and Yan, H. (2006), "Enhancing agility by timely sharing of supply information", Supply Chain Management, Vol. 11 No. 5, pp. 425-435. https://doi.org/10.1108/13598540610682444, Google Scholar

Lu, Y, and K. (Ram) Ramamurthy. (2011). Understanding the link between information technology capability and organizational agility: An empirical examination. Mis Quarterly, 931-954. DOI: https://doi.org/10.2307/41409967, Google Scholar

Magnificent, M. and Shekasteband, M. (2015). Impact of IT capabilities on business agility. Information Technology Management Studies, 1 (4), 1-24.

McGinnis, M. A., \& Vallopra, R. M. (1998). Purchasing and supplier involvement: new product development and production/operations process development and improvement. Tempe, AZ: Center for Advanced Purchasing Studies. Google Scholar

Mikalef, P. and Pateli, A. (2017). Information technology-enabled dynamic capabilities and their indirect effect on competitive performance: Findings from PLS-SEM and fsQCA. Journal of Business Research, 70, 1-16. https://doi.org/10.1016/j.jbusres.2016.09.004, Google Scholar

Mohammadi Moghaddam, Y, Dadfar, A. and Ghasht, A. (2016). Investigating the effect of organizational learning on organizational performance with respect to organizational agility mediator variable. Public Management Research, 9 (34), 243-265.

Mokhtarian Dehkordi, Sh (2017). The Role of Information Technology in Developing Strategic Agility and Improving Compet

Nadkarni, S. and Barr, S. S. (2008). Environmental context, managerial cognition, and strategic action: an integrated view. Strategic Management Journal, 29, 1395-1427. https://doi.org/10.1002/smj.717, Google Scholar

Ravichandran, T., Leong, Y. X., Teo, H. H., \& Oh, L. B. (2007). Service-oriented architecture and organizational integration: an empirical study of IT-enabled sustained competitive advantage. ICIS 2007 Proceedings, 92. Link, Google Scholar

Rezaian, A. and Ashouri, J. (2013). The impact of personality traits and the type of environment on the mutual decision of the members and the working team. Managerial Perspective, 15, 15-38.

Roberts N., and Grover, V. (2012). Leveraging information technology infrastructure to facilitate firm's customer agility and competitive activity: An empirical investigation. Journal of Management Information Systems, 28 (4), 231-270. https://doi.org/10.2753/MIS0742-1222280409, Google Scholar

Saha, N., Chatterjee, B., Gregar, A., and Saha, P. (2016). The impact of SHRM on sustainable organizational learning and performance development. International Journal of 
Organizational Leadership, 5 (1) 63-75. Available at SSRN: https://ssrn.com/abstract=3331830, Google Scholar

Sambamurthy, V., Bharadwaj, A., and Grover, V. (2003). Shaping agility through digital options: Reconceptualizing the role of information technology in contemporary firms. MIS quarterly, 237-263. DOI: https://doi.org/10.2307/30036530, JSTOR, Google Scholar

Shan, J. and Jolly, D. (2015). Technological innovation capabilities, product strategy, and firm performance: The electronics industry in China. Canadian Journal of Administrative Sciences, 30 (3), 159-172. https://doi.org/10.1002/cjas.1256, Google Scholar

Toure, N. and Khalili, M. (2016). Investigating the relationship between information technology and organizational agility in Mahabad Agricultural Bank. International Conference on Accounting and Management, Tehran.
Wang, Y., Chen, Y., Nevo, S., Jin, J. F., Tang, G. and Chow, W. S. (2013). IT capabilities and innovation performance: the mediating role of market orientation." Commun Assoc. Inf. Syst, 33. DOI: https://doi.org/10.17705/1CAIS.03309, Google Scholar

Weill, P., Subramani, M. and Broadbent, M. (2002). IT infrastructure for strategic agility. Sloan Management Review, 44 (1), 57-65. http://dx.doi.org/10.2139/ssrn.317307, Link, Google Scholar

Zott, C., Amit, R., and Massa, L. (2011). The business model: recent developments and future research. Journal of Management, 37 (4), 1019-1042. https://doi.org/10.1177/0149206311406265, Google Scholar 